\title{
Prevalence of dentigerous cysts due to impaction of mandibular third molar teeth
}

\author{
Hanifah Nuraini*, Harmas Yazid Yusuf*, Andri Hardianto* \\ *Department of Oral and Maxilofacial Surgery Faculty of Dentistry Universitas Padjadjaran
}

\section{ABSTRACT}

Dentigerous cyst is an odontogenic cyst that surrounds the crown of an impacted tooth, caused by fluid accumulation between the reduced enamel epithelium and the enamel surface, usually associated with mandibular third molars. The purpose of this study was to find out the prevalence of dentigerous cyst caused by impaction of mandibular third molar at the oral and maxillofacial surgery department of Hasan Sadikin hospital Bandung. This study was a descriptive survey study. Samples were taken from the data of patient's medical record from July 2006 until June 2011. The result of this study showed the number of oromaxillofacial cyst cases in the period was as much as $316(0.78 \%)$. Dentigerous cyst was the most common odontogenic cyst $(48,64 \%)$. Dentigerous cyst most commonly caused by impaction of the mandibular third molar $(13,89 \%)$. The amount of male and female patients with dentigerous cyst was the same ( $50 \%$ each). The most age group that suffered dentigerous cyst due to impaction of the mandibular third molars was the age group of $41-50$ years (40\%). The most chosen therapy was enucleation (100\%). From the results of this study can be concluded that dentigerous cyst due to impaction of mandibular third molars was the most common case, with the same frequency found in both male and female, the most age group of impacted was the age group of 41-50 years old, and the most chosen therapy was enucleation.

Keywords: Dentigerous cyst, impaction, mandibular third molar

\section{INTRODUCTION}

Impaction is the failure of a tooth to erupt to its normal position in the dental arch due to obstacles such as lack of space for eruption, in which the length of the alveolar bone is smaller compared to the total length of the dental arch. Many people experience tooth impaction, but this condition often ignored even when impacted teeth caused serious problems if left untreated. The problems that caused by tooth impaction such as infection, dental caries, ear disorders, pain, mandible fractures and the formation of odontogenic cysts and tumors.
One of cyst that caused by dental impaction is a dentigerous cyst. These cysts are seen around the teeth that do not erupt and mostly found in the third molar region, either the maxilla and the mandible, the upper canine region, and fewer found in the lower premolar region. ${ }^{1,2}$

Dentigerous cysts are one of the most common developmental odontogenic cysts (the second most common odontogenic cysts that often occur after radicular cysts), approximately impacted $20 \%$ of all jaw cysts. ${ }^{3,4}$

According to the research conducted at the Department of Oral and Maxillofacial Surgery of Al Arab Medical Sciences University, 37 cases of 
dentigerous cysts were associated with dental impaction, while radicular cysts were rarely found with dental impaction, which was less than $3 \% .{ }^{5}$

Dentigerous cysts grow without pain, except when there is an infection. These cysts are found by chance on a radiological examination or due to complaints of patients for the swellings which do not cause any pain. ${ }^{6}$ Most people will ignore a disease if there are no complaints, and they will just come to the doctor or the hospital only when there are symptoms or disturbing pain. Untreated dentigerous cysts can cause infections, pathologic fractures, shifting of the impacted tooth, and resorption of adjacent tooth roots. ${ }^{3}$

Based on the above background, we were interested in finding out and examined more about the prevalence of dentigerous cysts due to impaction of the mandibular third molar in Department of Oral and Maxillofacial Surgery of Hasan Sadikin Hospital Bandung, Indonesia. We chose Hasan Sadikin Hospital as the research place because Hasan Sadikin Hospital is a Top Referral Hospital for West Java and surrounding areas.

This study was conducted to obtain information regarding cases of dentigerous cysts due to impaction of the mandibular third molar in Department of Oral and Maxillofacial Surgery of Hasan Sadikin Hospital Bandung, Indonesia. The results of this study can be used as scientific information in the field of Oral and Maxillofacial Surgery for a reference for further research.

\section{METHODS}

The method used in this study was a descriptive survey method, conducted by collecting data from medical record card of patients attended Department of Oral and Maxillofacial Surgery of Hasan Sadikin Hospital Bandung, Indonesia, from July 2006 - June 2011.

The population in this study was the patient's medical record from Department of Oral and Maxillofacial Surgery of Hasan Sadikin Hospital from July 2006 - June 2011.

The sample in this study was the medical record of patients with dentigerous cysts due to impaction of the mandibular third molars.

This research was performed by collecting medical record card of patients attended Department of Oral and Maxillofacial Surgery of Hasan Sadikin Hospital from July 2006 - June 2011. After that followed by the examination and recording the total number of cases of cysts. Afterwards, it was identified and examined which cases were included into dentigerous cysts due to the impact of lower third molar teeth. The examination and data recording included the number of patients, age, sex, and therapy was performed after.

\section{RESULTS}

The results showed that there were as much as 40235 patients attended Department of Oral and Maxillofacial Surgery of Hasan Sadikin Hospital Bandung, Indonesia, and as much as 316 amongst them were suffering oromaxilofacial cyst with the average of $0.78 \%$ per year.

Table 2 showed that most odontogenic cyst types were dentigerous cysts with as much as 72 cases (48.64\%). The sequence of odontogenic cysts from the highest to the lowest was dentigerous cysts in 72 cases, radicular cysts in 56 cases, eruption cysts in 10 cases, 6 cases of odontogenic keratoses, 1 case of lateral periodontal cysts, residual cysts 1 case, and gingival cyst 1 case. There was also one case $(0.67 \%)$ of other odontogenic cysts that were not fully described in either clinical diagnosis or histopathologic examination results. The most non-odontogenic cyst types were mucocele cyst, which was found in as much as 118 cases, followed by ranula cyst in 38 cases, 5 cases of the palatal cyst, 2 globulomaxile cases, 1 case of the traumatic cyst, 1 case of lymphoepithelial cyst, 1 case of nasoalveolar cyst, and 1 case of nasolabial cyst. Besides odontogenic and nonodontogenic cysts, we also found 1 case of cysts in the maxillary region that were not fully described in clinical diagnosis.

Table 3 showed more dentigerous cysts occurred in the permanent teeth than the primary teeth. In primary teeth, the most common cause of dentigerous cyst was the impaction of the mandibular molar which was found in 4 teeth (5.55\%), followed by maxillary canines found in 3 teeth (4.17\%), maxillary canine and molar 2 maxilla which were found in 2 teeth $(2.77 \%)$, and mandibular canines as well as molar 2 mandible which were found in 1 tooth (1.39\%). While on the permanent tooth, dentigerous cyst was mostly 
Table 1. Amount of patients with oromaxillofacial cysts in Department of Oral and Maxillofacial Surgery of Hasan Sadikin Hospital Bandung, Indonesia, from July 2006 - June 2011

\begin{tabular}{cccc}
\hline Time & Amount of patients & Amount of cyst patients & Percentage of oromaxillofacial cyst patients \\
\hline July 2006 - June 2007 & 9656 & 91 & 0.94 \\
July 2007 - June 2008 & 8138 & 65 & 0.79 \\
July 2008 - June 2009 & 7649 & 30 & 0.39 \\
July 2009 - June 2010 & 7392 & 61 & 0.82 \\
July 2010 - June 2011 & 7400 & 69 & 0.93 \\
\hline Total & 40235 & 316 & 0.78 \\
\hline
\end{tabular}

Table 2. Distribution frequency of oromaxillofacial cysts patients based on type of cyst

\begin{tabular}{|c|c|c|c|c|c|c|c|}
\hline Type of cyst & $2006-2007$ & $2007-2008$ & $2008-2009$ & $2009-2010$ & $2010-2011$ & $\mathrm{~N}$ & $\%$ \\
\hline \multicolumn{8}{|c|}{ Odontogenic cysts } \\
\hline Dentigerous cysts & 21 & 18 & 12 & 12 & 9 & 72 & 48.64 \\
\hline Radicular cysts & 16 & 12 & 2 & 8 & 18 & 56 & 37.83 \\
\hline Eruption cysts & 3 & 0 & 1 & 5 & 1 & 10 & 6.75 \\
\hline Lateralis periodontal cysts & 1 & 0 & 0 & 0 & 0 & 1 & 0.67 \\
\hline Residual cysts & 0 & 0 & 0 & 0 & 1 & 1 & 0.67 \\
\hline Odontogenic keratosis & 4 & 0 & 0 & 1 & 1 & 6 & 4.05 \\
\hline Gingival cysts & 0 & 1 & 0 & 0 & 0 & 1 & 0.67 \\
\hline Odontogenic cysts & 0 & 0 & 0 & 1 & 0 & 1 & 0.67 \\
\hline Total & & & & & & 148 & 100 \\
\hline \multicolumn{8}{|c|}{ Non Odontogenic Cysts } \\
\hline Palatal cysts & 1 & 1 & 0 & 1 & 2 & 5 & 2.99 \\
\hline Globulomaxillary cysts & 0 & 1 & 0 & 0 & 1 & 2 & 1.19 \\
\hline Mucocele & 37 & 24 & 6 & 26 & 25 & 118 & 70.65 \\
\hline Ranula & 6 & 8 & 8 & 7 & 9 & 38 & 22.75 \\
\hline Traumatic cysts & 0 & 0 & 1 & 0 & 0 & 1 & 0.59 \\
\hline Lymphoepithelial cysts & 1 & 0 & 0 & 0 & 0 & 1 & 0.59 \\
\hline Nasoalveolar cysts & 1 & 0 & 0 & 0 & 0 & 1 & 0.59 \\
\hline Nasolabial cysts & 0 & 0 & 0 & 0 & 1 & 1 & 0.59 \\
\hline Total & & & & & & 167 & 100 \\
\hline $\begin{array}{l}\text { Cysts in the maxillary region } \\
\text { (no further information) }\end{array}$ & 0 & 0 & 0 & 0 & 1 & 1 & \\
\hline Grand Total & 91 & 65 & 30 & 61 & 69 & 316 & \\
\hline
\end{tabular}

caused by the impaction of the mandibular third molars whichhh was found in as much as 10 teeth (13.89\%), followed by the maxillary canine found in 9 teeth (12.5\%), insicivus 1 maxilla and insicivus 2 maxilla which were found in 4 teeth $(5.55 \%)$, molar 3 maxilla and premolar 1 maxilla which were found in 3 teeth $(4.17 \%)$, mandibular canines and premolar 2 mandibles which were found in 2 teeth (2.77\%), and molar 1 maxilla, insicivus 2 mandible, and molar 2 mandible which were found in 1 tooth (1.39\%). There were as much as 19 cases $(26.39 \%)$ of dentigerous cysts with unknown etiology due to incomplete data on the medical record.

Figure 1 showed the patients with dentigerous cysts due to impaction of lower third molars in male $(50 \%)$ was equal to female $(50 \%)$.

Table 4 showed the prevalence of dentigerous cysts due to the impaction of mandibular third molar teeth by age group. The most cases were found in the age group of 41-50 years old which was found in as much as 4 cases (40\%), 31-40 years old age group in 3 cases (30\%), 21-30 years old age group in 2 cases (20\%), and 51-60 years old age group in 1 case (10\%). There were no cases of 
Table 3. Distribution and frequency of dental impaction that caused dentigerous cysts

\begin{tabular}{|c|c|c|}
\hline Tooth Element & $F$ & $\%$ \\
\hline \multicolumn{3}{|c|}{ Primary teeth } \\
\hline Incisivus 1 maxilla & - & - \\
\hline Incisivus 2 maxilla & -3 & - \\
\hline Maxillary canine & 2 & 4.17 \\
\hline Molar 1 maxilla & 2 & 2.77 \\
\hline Molar 2 maxilla & - & 2.77 \\
\hline Incisivus 1 mandible & -1 & - \\
\hline Incisivus 2 mandible & 4 & - \\
\hline Mandibular canine & - & 1.39 \\
\hline Molar 1 mandible & 4 & - \\
\hline Molar 2 mandible & 4 & - \\
\hline Secondary teeth & 9 & 5.55 \\
\hline Incisivus 1 maxilla & 3 & 5.55 \\
\hline Incisivus 2 maxilla & -1 & 12.5 \\
\hline Maxillary canine & -3 & 4.17 \\
\hline Premolar 1 maxilla & -1 & 1.39 \\
\hline Premolar 2 maxilla & 2 & - \\
\hline Molar 1 maxilla & -2 & 4.17 \\
\hline Molar 2 maxilla & -1 & - \\
\hline Molar 3 maxilla & 10 & 1.39 \\
\hline Incisivus 1 mandible & 19 & 2.77 \\
\hline Incisivus 2 mandible & & - \\
\hline Mandibular canine & & 2.77 \\
\hline Premolar 1 mandible & & - \\
\hline Premolar 2 mandible & & 1.39 \\
\hline \multicolumn{3}{|l|}{ Molar 1 mandible } \\
\hline \multicolumn{3}{|l|}{ Molar 2 mandible } \\
\hline Molar 3 mandible & & 13.89 \\
\hline Incomplete data & & 26.39 \\
\hline Total & 72 & 100 \\
\hline
\end{tabular}

Figure 1. Prevalence of dentigerous cysts due to impaction of third mandibular molar based on gender

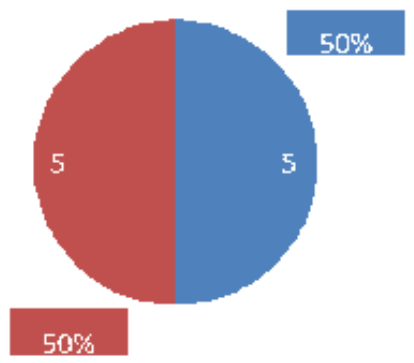

\section{nale}

n Female

dentigerous cysts due to impaction of mandibular third molar in the age group of 0-10 years old and more than 60 years old.
Table 4. Prevalence of dentigerous cysts due to impaction of mandibular third molar based on age group

\begin{tabular}{ccc}
\hline Age group & $\mathbf{n}$ & $\%$ \\
\hline $0-10$ & 0 & 0 \\
$11-20$ & 0 & 0 \\
$21-30$ & 2 & 20 \\
$31-40$ & 3 & 30 \\
$41-50$ & 4 & 40 \\
$51-60$ & 1 & 10 \\
$>60$ & 0 & 0 \\
\hline Total & 10 & 100 \\
\hline
\end{tabular}

Table 5. Types of treatment provided for patients with dentigerous cysts due to impaction of mandibular third molar

\begin{tabular}{ccc}
\hline Treatment & N & $\%$ \\
\hline Enucleation & 10 & 100 \\
Marsupialisation & - & - \\
\hline Total & 10 & 100 \\
\hline
\end{tabular}

Table 5 shows the type of treatment most commonly assigned to patients with dentigerous cysts due to impaction of lower third molars in this study is enucleation. The authors did not find dentigerous cysts due to impaction of lower third molars treated with marsupialisation in this study.

\section{DISCUSSION}

During the period from July 2006 to June 2011, the number of patients who came to the Surgical Division of Dr. Hasan Sadikin Hospital Bandung were 40235 people and 316 of them suffered from oromaxilofasial cysts.

Non odontogenic cyst type was the most common and the most common cases were 167 cases. The amount does not vary much with the type of odontogenic cysts, which amounted to 148 cases. This phenomenon differs from some literature which says that the most common odontogenic cysts are found compared to non odontogenic cysts. The most common type of odontogenic cysts found was dentigerous cysts which were found in 72 cases $(48.64 \%)$, followed by radicular cysts in 56 cases (37.83\%). This result was in contrast to the results of several studies, and the opinion of some literature stated that the most widely found odontogenic cysts were radicular cysts, followed by dentigerous cysts. 
Shafer et al. in 2006 suggested that radicular cysts were the most common odontogenic cysts found, followed by dentigerous cysts. ${ }^{4}$ The results of this study, however, was consistent with the results of the research conducted by Ramadhani in 2008 at Dental Polyclinics of Cipto Mangunkusumo National General Hospital which showed that dentigerous cysts were the most common case which was found in 45\% of the population, followed by radicular cysts which were found in $36.7 \%$ of the population. ${ }^{7}$ Differences in research results with existing theories may be influenced by environmental factors of society.

Table 4 showed that the most frequent cases of dentigerous cysts were caused by the impaction of the mandibular third molars, followed by the maxillary canines. This result was consistent with studies conducted by Coulthard in 2003 and Miloro in 2004 stated that the most frequent dentigerous cysts were caused by the impaction of the mandibular third molars followed by the maxillary canines. ${ }^{2,8}$ Mandibular third molars often suffer from a lack of room for normal eruption as it is the most recent eruption tooth. This condition resulted in a high frequency of dentigerous cysts in the mandibular third molars. The maxillary canine eruption after maxillary incisors at the age of 8-9 years old and maxillary premolar teeth at the age of 10-11 years old often caused the canine teeth suffer from a lack of room for eruption which can lead to impaction. Thus it can be concluded that the more likely the tooth is impacted, the higher chance of dentigerous cysts in the tooth region will occur.

According to gender-based groupings, dentigerous cysts due to the impaction of the mandibular third molars in male was the same as female (5 cases) (Figure 1). This result was inconsistent with studies conducted by Coulthard in 2003, Miloro in 2004, and Saraf in 2006 stated that dentigerous cysts were found more in male than female. ${ }^{2,8,9}$ Avelar et al. in 2009 had conducted a study at Universidade de Pernambuco Brazil, and also mentioned that cases of dentigerous cysts were found more in male $(63.5 \%)$, while in female was only found in as much as $36.5 \% .^{10}$ The high prevalence of dentigerous cysts in male is associated with the lack of awareness of the importance of oral health in the most male. The differences in the results of the study with existing theories may caused by a sample that is confined to the case of dentigerous cysts caused by the impaction of the mandibular third molars, not the whole case of dentigerous cysts.

Data on the prevalence of dentigerous cysts due to impaction of mandibular third molar by age group indicated that the case was most affected the age group of $41-50$ years old (40\%), the $31-40$ years old age group (30\%), the 21-30 years old age group (20\%), and the 5-60 years old age group $(10 \%)$. This result was in contrast to the statements of Neurology in 2006, and Miloro 2004 suggested that dentigerous cysts were mostly found in the patients aged from 10-30 years old. ${ }^{2,9}$ Differences in the results of the study with existing studies may caused by the samples limitation to dentigerous cysts caused by mandibular third molars, not the whole case of dentigerous cysts. Also, long periods of time research can also be one of the causes of this difference. The high incidence of dentigerous cysts due to the impaction of mandibular third molars in the 41-50 year age group may caused by the presence of untreated impaction teeth over the long periods of time that develop into dentigerous cysts, along with clinical features of asymptomatic dentigerous cysts.

The type of treatment for patients with dentigerous cysts due to mandibular third molar impaction mostly found in this study was enucleation. This result may caused by easier enucleation technique, no further surgery required because the cysts are removed entirely, and the potential for case recurrence is small. However, the enucleation technique also has a disadvantage, which is it cannot be done for larger lesions and thinner bones because it can cause a fracture. ${ }^{11}$ The authors did not find dentigerous cysts due to impaction of lower third molar treated with marsupialization technique. Based on this research marsupialization technique was performed in most cases of the ranula cysts. Marsupialization techniques are also performed on some dentigerous cysts in other regions besides the mandibular third molar. This technique usually performed on large cysts. Marsupialization has an easy procedure and can keep the vital structure from damage at the time of enucleation. The deficiency of the marsupialization technique is the presence of partially abandoned cyst membranes potential for case recurrence. ${ }^{11,12}$ 


\section{CONCLUSION}

From the results of this study can be concluded that dentigerous cyst due to impaction of mandibular third molars was the most common case, with the same frequency found in both male and female, the most age group of impacted was the age group of 41-50 years old, and the most chosen therapy was enucleation.

\section{REFERENCES}

1. Wray D, Stenhouse D, Lee D, Clark AJE. Textbook of general and oral surgery. London: Churchill Livingstone; 2003.

2. Miloro M, Ghali GE, Larsen P, Waite P. Peterson's principles of oral and maxillofacial surgery. $2^{\text {nd }}$ ed. Shelton: People's Medical Publishing House; 2004.

3. Neville BW, Damm DD, Allen CM, Bouquot JE. Oral and maxillofacial pathology, $2^{\text {nd }}$ ed. Philadelphia: Saunders-Elsevier; 2002.

4. Shafer, Hine, Levy, Rajendran R, Sivapathasundharam B. Shafer's textbook of oral pathology. $5^{\text {th }}$ ed. New Delhi: Reed Elsevier India Pt. Ltd.; 2006.

5. El Gehani R, Khrisnan B, Orafi H. The prevalence of inflammatory and developmental odontgenic cyst in a Libyan population. Libyan J Med. 2008;3(2):75-77.

6. Danudiningrat CP. Kista Odontogen dan Nonodontogen. Surabaya: Airlangga University Press; 2006.

7. Ramadhani DN. Distribusi dan frekuensi kista dentigerous berdasarkan elemen gigi penyebab dan lokasi kelainan di poli gigi RSUPN Cipto Mangunkusumo [minor thesis]. Jakarta: UI: 2008.

8. Coulthard P, Horner K, Sloan P, Theaker E. Oral and maxillofacial surgery, radiology, pathology and oral medicine. London: Churchill Livingstone; 2003.

9. Saraf S. Textbook of oral pathology. $1^{\text {st }}$ ed. New Delhi: Jaypee Brothers; 2006.

10. Avelar RL, Antunes AA, Carvalho RW, Bezerra PG, Oliveira Neto PJ, Andrade ES. Odontogenic Cysts: A Clinicopathological Study of 507 Cases. J Oral Sci. 2009 Dec;51(4):581-6.

11. Peterson LJ, Ellis E, Hupp JR, Tucker MR. Contemporary Oral and Maxillofacial Surgery. $4^{\text {th }}$ ed. St. Louis: Mosby-Elsevier; 2003.

12. Peterson LJ, Hupp JR. Contemporary Oral and Maxillofacial Surgery, $5^{\text {th }}$ ed. St. Louis: MosbyElsevier; 2008 